\title{
Measuring the Social Net Benefits of COVID-19 Restrictions: The Case of Reduced Vehicle Use in a Pollution-Prone Region of Utah
}

\author{
Ethan Hartley ${ }^{1}$, Arthur J. Caplan ${ }^{2 *}$ \\ ${ }^{1}$ Department of Economics, University of Hawai'i at Mänoa, Honolulu, USA \\ ${ }^{2}$ Department of Applied Economics, Utah State University, Logan, USA \\ Email: *arthur.caplan@usu.edu
}

How to cite this paper: Hartley, E. and Caplan, A.J. (2021) Measuring the Social Net Benefits of COVID-19 Restrictions: The Case of Reduced Vehicle Use in a Pollution-Prone Region of Utah. Journal of Environmental Protection, 12, 887-902. https://doi.org/10.4236/jep.2021.1211052

Received: October 14, 2021

Accepted: November 21, 2021

Published: November 24, 2021

Copyright $\odot 2021$ by author(s) and Scientific Research Publishing Inc. This work is licensed under the Creative Commons Attribution International License (CC BY 4.0).

http://creativecommons.org/licenses/by/4.0/

\begin{abstract}
A number of natural experiments have recently found that COVID-19 restrictions imposed in nations worldwide are correlated with short-term reductions-in some cases dramatic reductions-in mobile-source air pollutants. Noticeably absent from these studies are estimates of the social net benefits associated with the changes in human behavior underlying the pandemic-induced effects. Using readily available data provided by the state of Utah and the U.S. Environmental Protection Agency's Co-Benefits Risk Assessment Health Impacts Screening and Mapping Tool (COBRA), we find that daily social net benefit was positive during a pandemic-induced shutdown from March to April, 2020 in Utah's Wasatch Front region solely when COBRA's "high" health benefit estimate from combined reductions in $\mathrm{PM}_{2.5}$ and $\mathrm{NO}_{\mathrm{x}}$ concentrations are weighed against the region's "low" vehicle-trip cost estimate. All other scenarios correspond with negative net benefit estimates, i.e., when high and low benefit estimates of reductions solely in $\mathrm{PM}_{2.5}$ concentrations as well as for combined reductions in $\mathrm{PM}_{2.5}$ and $\mathrm{NO}_{\mathrm{x}}$ concentrations are weighed against the region's high vehicle-trip cost estimate. Generally speaking, social net benefits are higher for two of the Wasatch Front's four counties.
\end{abstract}

\section{Keywords}

Social Net Benefits, COVID-19 Restrictions, Mobile-Source Air Pollution

\section{Introduction}

Social scientists in general, and economists in particular, are continually (and unapologetically) on the lookout for crises or turn-of-events that foster natural 
experimentation, where changes in human behavior trigger measurable consequences. It should therefore come as no surprise that social scientists have more recently seized upon the myriad opportunities engendered by the COVID-19 pandemic and its attendant economic implications to design natural and quasiexperiments and test for the pandemic's shorter-term effects on human behavior. Plentiful examples of pandemic-inspired experiments have emerged in the literature (c.f., [1] [2] [3]).

Experiments devoted to the measurement of the COVID-19 pandemic's impacts on air quality are particularly numerous. For example, [4] estimate that during the period of prevention and control in China, the average metropolitan area's particulate matter and nitrogen dioxide $\left(\mathrm{NO}_{2}\right)$ concentration levels dramatically decreased, and its corresponding air quality index (AQI) significantly improved. However, continued operation of essential industries during the prevention and control period, such as thermal power plants, likely precluded similar declines in the emissions of sulfur dioxide $\left(\mathrm{SO}_{2}\right)$ and carbon monoxide (CO). Ground-level ozone concentrations were also not found to have changed significantly in the short term. Overall, a positive correlation was found between more daily confirmed COVID-19 cases and improvements in air quality. See [5] [6] [7] for additional findings from China.

Similar results are found for India by [8]. Metropolitan areas nationwide experienced significant reductions in $\mathrm{NO}_{2}$ and $\mathrm{PM}_{2.5}$ concentrations during the lockdown period. Coarse particulate matter $\left(\mathrm{PM}_{10}\right)$, and ground-level ozone concentrations also showed substantial reductions, whereas $\mathrm{CO}$ concentrations exhibited a moderate decline. Similar to [4], $\mathrm{SO}_{2}$ concentration levels did not show any defined reduction trends and increased in the cities of Mumbai, Bengaluru, and Kolkata. Similar reductions in $\mathrm{PM}_{2.5}, \mathrm{CO}$, and $\mathrm{NO}_{2}$ concentration levels in Pittsburgh, Pennsylvania are found by [9] as a consequence of COVID-19 related closures, particularly at otherwise high-traffic sites during rush hours. However, the authors found no significant change in industry-related intraday variability of $\mathrm{CO}$ and $\mathrm{PM}_{2.5}$ concentration levels in response to the enactment of COVID-19 control measures.

In the study most related to ours, [10] examine vehicle use and air quality data from a mixed commercial-residential neighborhood in Somerville (MA, USA), where traffic is the dominant source of air pollution. Measurements were made from the end of March until mid-May, 2020, coinciding with a dramatic reduction in traffic (a roughly 70\% decline in car and near 50\% decline in truck traffic) due to business shutdowns and a statewide stay-at-home COVID-19 advisory. Concentrations linked to vehicular emissions of particulate matter and black carbon were measured with a mobile monitoring platform on an interstate highway and major and minor roadways. The authors' results show that depending on road class, median particulate and black carbon contributions from traffic were anywhere from $60 \%-70 \%$ and $20 \%-45 \%$ lower, respectively, during the lockdown compared to pre-pandemic levels. Corresponding reductions in car 
and truck traffic were roughly $45 \%-70 \%$ and $20 \%-55 \%$, respectively.

Noticeably absent from these studies are estimates of the social net benefits associated with the changes in human behavior underlying the pandemic-induced effects (notwithstanding [11], which develops an interesting empirical approach to measure public health benefits associated with reductions in cumulative confirmed COVID-19 (CCC) cases using total capitalization of 14 stock market indices for large-cap stocks, as well as an estimated elasticity of CCC cases obtained from a panel-data analysis of daily observations from the third week of January to the first week of April, 2020). Identifying and quantifying an effect is clearly a necessary first-step. But additional steps are needed if the goal is to then translate the measured effect into its associated social net benefit. In this paper, we demonstrate how to derive an estimate of the social net benefit associated with a pandemic-induced slowdown in economic activity that normally contributes to a persistent, local air pollution problem. This problem-elevated $\mathrm{PM}_{2.5}$ concentrations experienced by residents of the Wasatch Front region in Utah primarily during the winter-inversion season-is tied mainly to region-wide vehicle usage. As such, estimating the health damages avoided as a result of the pandemic-induced reduction in concentrations, and comparing these savings with an estimate of the attendant costs incurred by households as they reduced their vehicle usage, enables us to weigh the estimates against each other to determine the social net benefit associated with COVID-19's impact on mobile-source air pollution in the Wasatch Front.

Utilizing 1) the prevailing estimate of the reduction in the average daily $\mathrm{PM}_{2.5}$ concentration level experienced by the Wasatch Front from March 2019 (pre-COVID-19 restriction period) to March 2021 (COVID-19 restriction period), and 2) our own range of estimated declines in region-wide vehicle trips recorded across the same two periods of time, we apply the US Environmental Protection Agency's (EPA's) Co-Benefits Risk Assessment Health Impacts Screening and Mapping Tool (COBRA) to estimate the health benefits associated with reductions in $\mathrm{PM}_{2.5}$ concentrations, along with published estimates in the literature of the cost of foregone vehicle trips, to determine the social net benefits of COVID-19 restrictions in Utah's Wasatch Front (The COBRA simulation tool and user manual are available at https://www.epa.gov/cobra).

We find that daily social net benefit is positive for the region as a whole solely when COBRA's "high" health benefit estimate from combined reductions in $\mathrm{PM}_{2.5}$ and $\mathrm{NO}_{\mathrm{x}}$ concentrations are weighed against the region's "low" vehicle-trip cost estimate. All other scenarios correspond with negative benefit estimates, i.e., when high and low benefit estimates of reductions solely in $\mathrm{PM}_{2.5}$ concentrations as well as for combined reductions in $\mathrm{PM}_{2.5}$ and $\mathrm{NO}_{\mathrm{x}}$ concentrations are weighed against the region's high vehicle-trip cost estimate. This pattern of social net benefits for the Wasatch Front as a whole is not uniform across the region's different counties. Generally speaking, social net benefits are higher for Davis and Salt Lake Counties than for Utah and Weber Counties (pertinent 
information about each county is provided in the next section).

Our results, therefore, suggest that the mitigatory effects of COVID-19 restrictions on metropolitan-area pollution levels reported by [4] [8] [9] and [10] should be interpreted with a degree of caution. While obviously worth heralding, the pandemic-induced reductions in air pollution levels estimated in these studies may nevertheless fail to pass social cost-benefit tests when the economic costs of what was foregone to achieve the reductions are accounted for.

The next section provides a brief description of Utah's Wasatch Front region, a region prone to episodic elevations in $\mathrm{PM}_{2.5}$ concentration levels during the winter months and therefore amenable to natural experiments associated with any short-term environmental shocks that might lead to sudden changes in these levels. Section 3 presents our estimates of the impacts of the region's COVID-19 restrictions on its vehicle usage, $\mathrm{PM}_{2.5}$ concentrations, and associated public health outcomes. These impacts are captured by highly aggregated, secondary sources of data. Section 4 describes our COBRA estimates of the health benefits associated with the regional reductions in concentrations, as well as the corresponding cost estimates of foregone vehicle trips. Together, these estimates enable us to derive an array of social net benefit measures. Section 5 summarizes our findings and expounds upon the advantages of our method, but also reminds the reader of the method's key limitation.

\section{Utah's Wasatch Front}

The Wasatch Front is a sprawling metropolitan region located in north-central Utah (see Figure 1). It consists of a collection of contiguous cities stretching along the Wasatch Mountain Range from approximately Nephi in the south to Brigham City in the north. Roughly 80 percent of Utah's population resides in

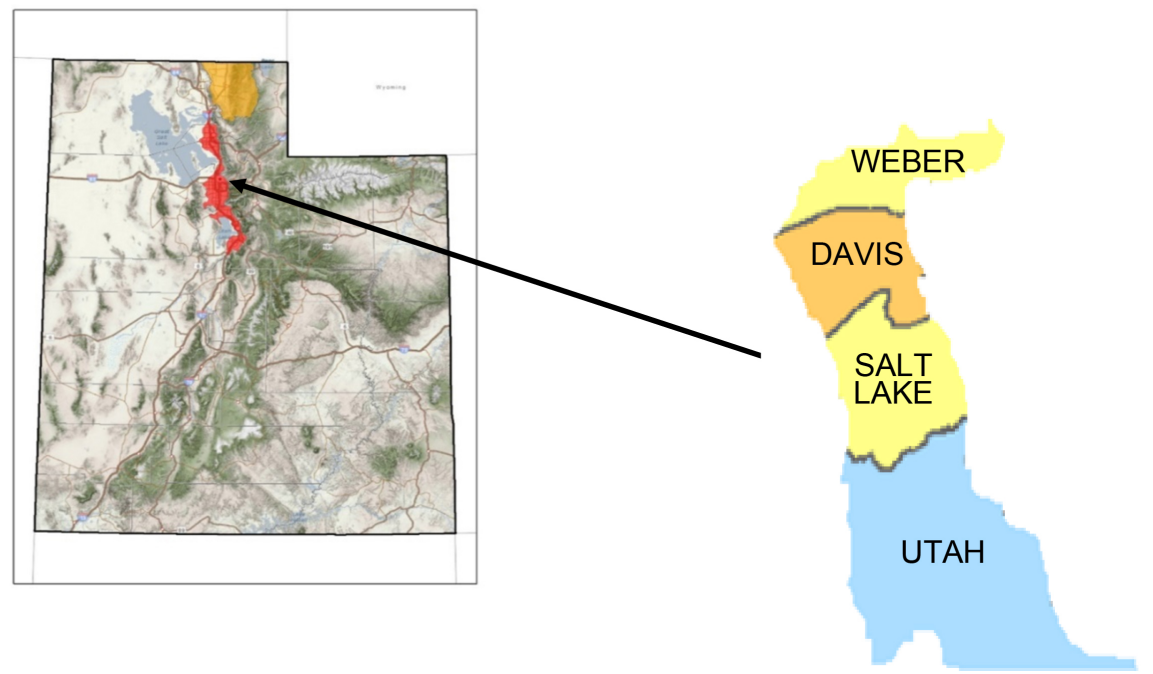

Figure 1. Utah's Wasatch Front (highlighted red with breakout of specific counties)*. ${ }^{*}$ Scale: The state of Utah encompasses roughly 85,000 square miles in total. The four Wasatch Front Counties of Weber, Davis, Salt Lake, and Utah together encompass 4230 square miles. 
the region (2.5 million people), which contains the state's capital, Salt Lake City, and accounts for almost 90 percent of the state's gross state product [12].

The Wasatch Front has experienced considerable growth since the 1950s-its population increasing by over $300 \%$ to its current 2.5 million residents, with projections of the population reaching six million residents by 2065 [13]. Much of the remaining undeveloped land is rapidly being developed, forcing local governments and regional authorities to contend with problems of urban sprawl and related transportation issues. According to [13]'s projections, just under $30 \%$ of Utah's population will reside in Utah County by 2065 , as will $40 \%$ of new residents to the state during this 50 -year time span. Just over $20 \%$ of new residents will reside in Salt Lake County, currently the Wasatch Front's most populous county. Forty and roughly $25 \%$ of those employed in the state are projected to be working in Salt Lake and Utah Counties, respectively, by 2065. Davis County is projected to experience the state's third highest employment growth rate during this same time frame.

The Wasatch Front is emblematic of a fast-growing metropolitan area known for its abundance of quality-of-life attributes, such as convenient access to outdoor recreation, ample job opportunities, and pockets of progressive urban growth [14] [15]. But as [16] points out, over the past two decades the region has been plagued by persistently poor air quality, particularly during the winter months when episodic temperature inversions entrap vehicle emissions, in turn elevating the region's $\mathrm{PM}_{2.5}$ concentrations ([17] estimates that roughly $60 \%$ of $\mathrm{PM}_{2.5}$ concentrations in the Wasatch Front region are attributable to mobile-source emissions). The problem is severe-the Wasatch Front has been repeatedly ranked by the American Lung Association (ALA) as one of the nation's ten worst metropolitan areas for short-term particulate concentrations [18].

The region's residents have expressed a strong desire for improvements in environmental-protection and resource-management policies that have not kept pace with the region's development over time. According to [19], Wasatch Front residents believe that mitigation of poor air quality should be the state's second-highest priority, tied with funding of public education and only slightly behind management of water resources. Survey results indicate that, inter alia, over 60 percent of respondents believe air quality negatively impacts their lives, over 90 percent believe good air quality is integral in maintaining good health, and almost 80 percent believe air quality has worsened in the Greater Wasatch and Northern Utah regions over the past 20 years. Further, residents identify changes in how they transport themselves (i.e., changes in the extent to which they contribute mobile-source emissions), e.g., telecommuting, ridesharing, use of public transit, reduced idling and unnecessary driving, as being the most beneficial approaches to improving air quality.

As discussed in [16], the state of Utah and various Wasatch Front regional authorities have not been completely idle in addressing the issue of episodic air pollution outbreaks, or what is commonly known as the occurrence of "red air days" during the winter months. Indeed, several lines of action have emerged 
over time. On the legislative front, the bipartisan Clean Air Caucus has introduced bills in the state legislature seeking funding for clean-fuel school buses, extension of corporate and individual tax credits for energy-efficient vehicles, and the sponsorship of a variety of competitions aimed to raise awareness of both the problem and actions that can be taken at the household and commercial levels to mitigate it [20]. Further, emissions testing programs require tests every two years on all vehicles registered in the Wasatch Front region with model years less than six years old, unless the model year is 1967 or older [21]. Further, the state actively promotes changes in transportation behavior, e.g., carpooling, use of public transit, teleworking, trip chaining, alternative work schedules, etc., through its Travelwise program [22]. In conjunction with statewide efforts to address the problem, several non-profit organizations advocate and educate for greater awareness of the problem, e.g., Utah Physicians for a Healthy Environment, Breathe Utah, and Heal Utah. Despite these concerted efforts on the part of governmental agencies and non-profit organizations, the Wasatch Front's red-air-day problem has stubbornly persisted.

\section{COVID-19's Impacts on Vehicle Use, $\mathrm{PM}_{2.5}$ Concentrations, and Public Health Outcomes in Utah's Wasatch Front Region}

On March 6, 2020, Utah Governor Gary Herbert declared a state of emergency and enacted a statewide "Stay Safe, Stay Home" policy in response to a surge in the state's COVID-19 infection rate. Ten days later, Salt Lake County issued a public health order closing many business and places of mass gathering. According to [23], these actions by state and regional authorities resulted a rapid decrease in emissions from vehicle traffic, which in turn noticeably improved the Wasatch Front's air quality. From March 15 to March 31, 2020, roughly two weeks after Salt Lake County's shutdown measures were promulgated, [23] estimates that $\mathrm{NO}$ and $\mathrm{NO}_{2}$ concentrations were $57 \%$ and $36 \%$ lower, respectively, than their long-term averages for this same time period. The reductions in NO were particularly apparent during morning and evening rush hour periods, while $\mathrm{NO}_{2}$ was lower throughout the day. Concentrations of $\mathrm{PM}_{2.5}$ were estimated to have decreased by $41 \%$ during this period (the percentage reductions in $\mathrm{PM}_{2.5}, \mathrm{NO}$, and $\mathrm{NO}_{2}$ concentrations reported by [23] fall within the range of reductions reported by [4] [8] [9] and [10] for these pollutants).

To illustrate these differences in concentration levels, [23] provide satellite $\mathrm{NO}_{2}$ observations of the Wasatch Front from the Tropomi instrument on the Sentinal-5 satellite (see Figure 2). In the figure, red coloring indicates higher $\mathrm{NO}_{2}$ concentrations. The difference in average conditions between the March 15 and $3+0$ periods in 2019 and 2020 are stark. As [23] points out, having both ground- and satellite-based observations in agreement with each other provides additional confidence in the magnitude of air quality improvements during the Wasatch Front's COVID-19 lockdown in March of 2020. 


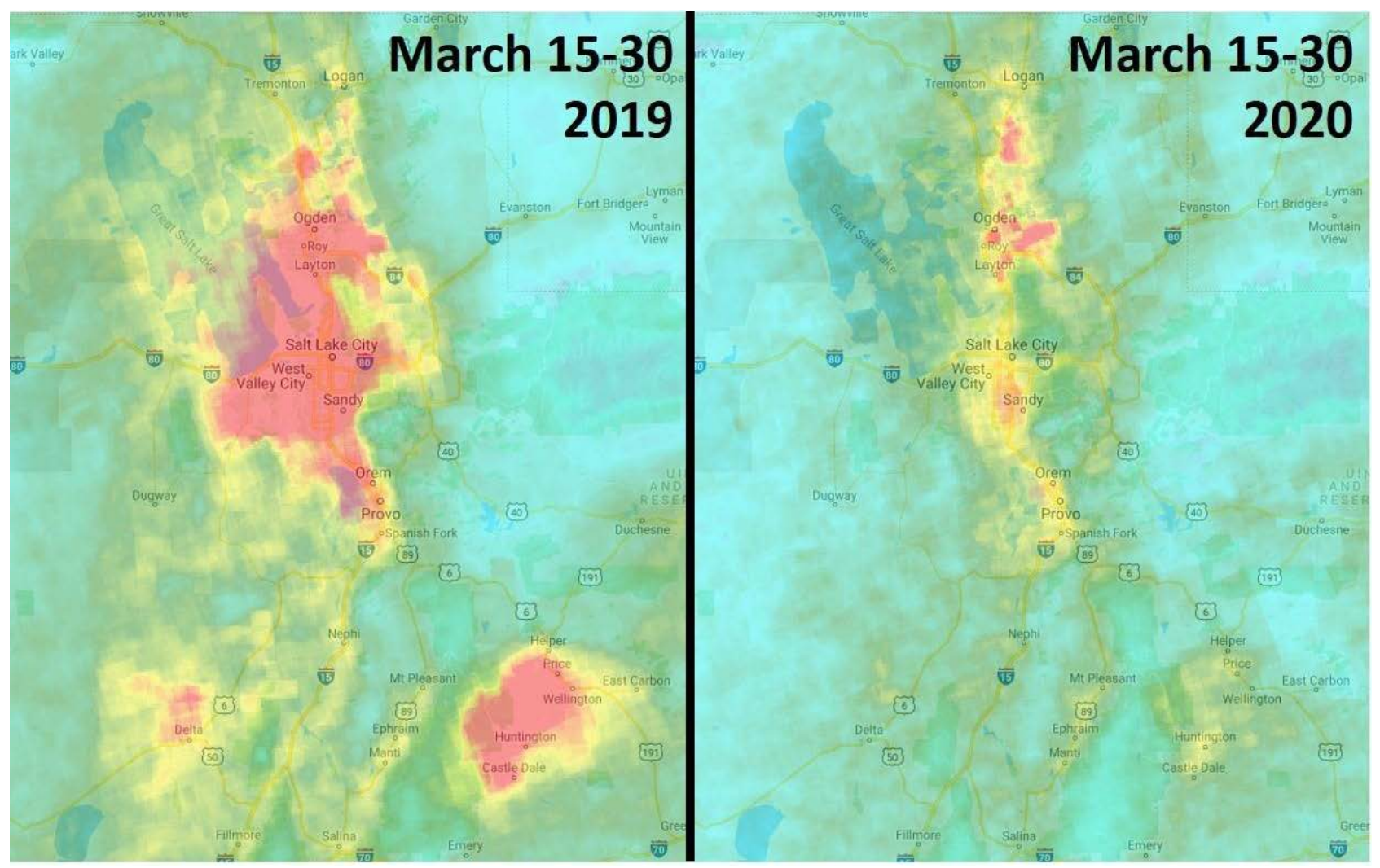

Figure 2. Comparison of $\mathrm{NO}_{2}$ concentrations in Utah's Wasatch Front late March 2019 vs. 2020.

We inputted [23]'s estimates of $41 \%, 57 \%$, and $36 \%$ reductions in $\mathrm{PM}_{2.5}, \mathrm{NO}$, and $\mathrm{NO}_{2}$ concentration levels (attained during the Wasatch Front's COVID-19 lockdown period) into the EPA's COBRA program in order to generate estimates of corresponding regional health benefits. COBRA contains detailed EPA estimates of $\mathrm{PM}_{2.5}, \mathrm{SO}_{2}, \mathrm{NO}_{\mathrm{X}}$ (combined $\mathrm{NO}$ and $\mathrm{NO}_{2}$ ), ammonia $\left(\mathrm{NH}_{3}\right)$, and volatile organic compounds (VOCs) concentration levels calibrated for the year 2017. Users create their own scenarios by specifying increases or decreases to county-, state-, or national-level baseline emission estimates. COBRA uses a reduced-form air quality model, the Source-Receptor (S-R) Matrix, to estimate the effects of emission changes on ambient $\mathrm{PM}_{2.5}$ concentrations. Using an approach to estimate avoided health impacts and monetized benefits that is generally consistent with EPA practice, the COBRA model translates changes in ambient $\mathrm{PM}_{2.5}$ concentration levels into public health effects and monetizes them (https://www.epa.gov/cobra).

Table 1 presents our COBRA results for each of the four Wasatch Front Counties based upon [23]'s estimates of 1 ) a sole $41 \%$ reduction in the region's $\mathrm{PM}_{2.5}$ concentrations, and 2) a combined $41 \%$ reduction in the region's $\mathrm{PM}_{2.5}$ concentrations, $57 \%$ reduction in $\mathrm{NO}$ concentrations, and $36 \%$ reduction in $\mathrm{NO}_{2}$ concentrations. For both of these cases, we assume the reductions in concentration levels occur uniformly across the four counties. Results are presented for both daily high and low public health benefit estimates obtained from COBRA. 
Table 1. COBRA estimates of daily public health benefits for Utah's Wasatch Front.

\begin{tabular}{ccccc}
\hline \multirow{2}{*}{ County } & \multicolumn{2}{c}{$\begin{array}{c}\text { Reductions in } \mathbf{P M}_{2.5} \\
\text { Concentrations }(\$)\end{array}$} & $\begin{array}{c}\text { Reductions in } \mathbf{P M}_{2.5}, \mathbf{N O}, \\
\text { and } \mathbf{N O}_{\mathbf{x}} \text { Concentrations (\$) }\end{array}$ \\
\cline { 2 - 5 } & $\begin{array}{c}\text { Low } \\
\text { Estimate }\end{array}$ & $\begin{array}{c}\text { High } \\
\text { Estimate }\end{array}$ & $\begin{array}{c}\text { Low } \\
\text { Estimate }\end{array}$ & $\begin{array}{c}\text { High } \\
\text { Estimate }\end{array}$ \\
\hline Davis & 24,358 & 54,760 & 53,075 & 119,287 \\
Salt Lake & 84,938 & 191,328 & 196,306 & 442,037 \\
Utah & 13,831 & 31,041 & 37,751 & 84,705 \\
Weber & 14,743 & 33,168 & 34,222 & 76,971 \\
Wasatch Front & 137,870 & 310,297 & 321,354 & 723,000 \\
\hline
\end{tabular}

The distinction between the table's high and low estimates is based solely upon the sensitivity of COBRA's estimates for mortality and nonfatal heart attacks. Sensitivities of the other categories comprising COBRA's overall public health estimates associated with reductions in $\mathrm{PM}_{2.5}, \mathrm{NO}$, and $\mathrm{NO}_{2}$ concentrations-pertaining to infant mortality, hospital admissions for upper and lower respiratory ailments, asthma, chronic lung disease, and nonfatal cardiovascular conditions, acute bronchitis, asthma exacerbation, emergency room visits, minor restricted activity days, and work loss days-do not exhibit such sensitivity and are therefore not adjusted in the determination of high versus low aggregate public health benefits. High estimates are roughly double the low estimates for each county, and thus for the Wasatch Front as a whole.

It is interesting to note that the differences inpublic health benefits across counties do not track corresponding differences in population sizes. For example, although Salt Lake County's population size of over 1.16 million is by far the Wasatch Front's largest, in turn corresponding to the region's highest estimates of dailypublic health benefits associated with a reduction in $\mathrm{PM}_{2.5}$ concentrations (low estimate of roughly $\$ 85,000$ and high estimate of over $\$ 191,000$ ), the county with the next highest population size-Utah County, with a population of just over 670,000-records the lowest daily benefits of the four Wasatch Front Counties from reductions in $\mathrm{PM}_{2.5}$ concentrations (COBRA reports annualized benefit estimates, which we have converted to their daily equivalents. Population estimates are taken from [24]). Davis County's population size of just under 360,000 (the region's third lowest) corresponds to the region's second-highest estimated benefits from reductions in $\mathrm{PM}_{2.5}$ concentrations (low estimate of just over $\$ 24,000$, high estimate of almost $\$ 55,000$ ).

These differences result from differences in the demographic compositions of the four counties. The populations of Davis and Salt Lake Counties are each comprised of higher proportions of at-risk seniors and other demographic groups more sensitive poor air quality than are the populations of Utah and Weber Counties, which in turn results in relatively larger public health benefits for Davis and Salt Lake Countiesas $\mathrm{PM}_{2.5}$ concentrations are reduced [25] [26].

We can think of the public health estimates for the combined reductions in 
$\mathrm{PM}_{2.5}$, NO, and $\mathrm{NO}_{2}$ concentration levels as instead combined reductions in $\mathrm{PM}_{2.5}$ and $\mathrm{NO}_{\mathrm{x}}$ (which is combined $\mathrm{NO}$ and $\mathrm{NO}_{2}$ ) concentration levels. Because COBRA bases benefit estimates upon reductions in $\mathrm{NO}_{\mathrm{x}}$ rather than separate reductions in $\mathrm{NO}$ and $\mathrm{NO}_{2}$, we assume that the $\mathrm{NO}_{\mathrm{x}}$ reduction is equal to the average of $\mathrm{NO}$ and $\mathrm{NO}_{2}$ reductions, in this case equaling $46.5 \%$. This is admittedly a higher percent than if we had just used the $36 \%$ reduction in $\mathrm{NO}_{2}$ (since $\mathrm{NO}$ is rapidly converted to $\mathrm{NO}_{2}$, it is sometimes considered a surrogate for $\mathrm{NO}_{\mathrm{x}}$ ). However, others believe that both $\mathrm{NO}$ and $\mathrm{NO}_{2}$ should be considered $\mathrm{NO}_{\mathrm{x}}$ [27].

As anticipated, both the low and high estimates in Table 1 of daily public health benefits associated with combined reductions in $\mathrm{PM}_{2.5}$ and $\mathrm{NO}_{\mathrm{x}}$ concentration levels are more than double for each Wasatch Front County with respect to the benefit estimates associated solely with reductions in $\mathrm{PM}_{2.5}$ concentrations. In contrast to the benefits associated with solely the estimated reductions in $\mathrm{PM}_{2.5}$ concentrations, Utah County's estimated daily benefits exceed Weber County's when reductions in $\mathrm{PM}_{2.5}$ concentrations are combined with reductions in $\mathrm{NO}_{\mathrm{x}}$ concentrations.

Table 2 presents results for the associated reductions in average, daily, county-wide vehicle trips from March-April 2019 to March-April 2020 using Utah Department of Transportation's (UDOT's) publicly provided data [28]. We see that these estimated reductions range from just over $17 \%$ for Davis County to almost $27 \%$ for Salt Lake County. The corresponding $\mathrm{PM}_{2.5}$ elasticities are calculated as the estimated pandemic-induced percentage reduction in $\mathrm{PM}_{2.5}$ concentration of $41 \%$ divided by a given county's percentage reduction in average daily vehicle trips. For example, Davis County's $\mathrm{PM}_{2.5}$ elasticity is determined as $0.41 / 0.172=2.38$, and so on for the remaining counties. Similarly, the associated $\mathrm{NO}_{\mathrm{x}}$ elasticities are calculated as the estimated pandemic-induced percentage reduction in $\mathrm{NO}_{\mathrm{x}}$ concentration of $46.5 \%$ divided by a given county's percentage reduction in average daily vehicle trips. Because the $\mathrm{PM}_{2.5}$ elasticities reported in Table 2 are larger than the estimated $\mathrm{PM}_{2.5}$ elasticity of 1.00 reported in [29] for Cache County, Utah, we discuss the implications of constraining our $\mathrm{PM}_{2.5}$

Table 2. Estimated reductions in mean daily trip counts and associated elasticities and costs for Utah's Wasatch Front.

\begin{tabular}{|c|c|c|c|c|c|c|c|}
\hline \multirow{2}{*}{ County } & \multicolumn{3}{|c|}{ Mean Daily Trip Count (\# vehicle trips) } & \multicolumn{2}{|c|}{ Elasticities } & \multicolumn{2}{|c|}{$\begin{array}{l}\text { Daily Cost of Trip } \\
\text { Count Decrease }(\$)\end{array}$} \\
\hline & $\begin{array}{c}\text { March-April } \\
2019\end{array}$ & $\begin{array}{c}\text { March-April } \\
2020\end{array}$ & \% Reduction & PM2.5 & Nox & Low Cost & High Cost \\
\hline Davis & 58,906 & 48,768 & 17.2 & 2.38 & 2.70 & 42,580 & 93,777 \\
\hline Salt Lake & 127,488 & 93,351 & 26.8 & 1.53 & 1.74 & 143,375 & 315,767 \\
\hline Utah & 84,510 & 62,122 & 26.5 & 1.55 & 1.76 & 94,030 & 207,089 \\
\hline Weber & 51,817 & 39,779 & 23.2 & 1.76 & 2.00 & 50,560 & 111,352 \\
\hline $\begin{array}{l}\text { Wasatch } \\
\text { Front }\end{array}$ & 322,721 & 244,020 & 24.4 & 1.68 & 1.91 & 330,544 & 727,984 \\
\hline
\end{tabular}


Table 3. Daily social net benefit estimates for Utah's Wasatch Front.

\begin{tabular}{ccccc}
\hline & \multicolumn{2}{c}{$\begin{array}{c}\text { Reductions in } \mathrm{PM}_{2.5} \\
\text { Concentrations (\$) }\end{array}$} & \multicolumn{2}{c}{$\begin{array}{r}\text { Reductions in } \mathrm{PM}_{2.5} \text { and } \mathrm{NO}_{\mathbf{x}} \\
\text { Concentrations (\$) }\end{array}$} \\
\cline { 2 - 5 } & Low Benefit & High Benefit & Low Benefit & High Benefit \\
\hline Low Cost & $-192,674$ & $-20,247$ & -9191 & 392,456 \\
High Cost & $-590,114$ & $-417,687$ & $-406,631$ & -4985 \\
\hline
\end{tabular}

elasticities to equaling 1.00 in Section 4.

Lastly in Table 2, we apply both "low" and "high" estimates of the per-trip benefit associated with a vehicle trip to the estimated reductions in county-wide vehicle trips in order to derive estimates of the average, daily, county-wide costs of the decreases in vehicle trips that occurred in the Wasatch Front in response to the COVID-19 shutdown in March-April, 2020. Our low estimate of $\$ 4.20$ per vehicle trip is derived from [30] [31] [32], while our high estimate of $\$ 9.25$ is taken from [33] [31]. Hence, the low-cost estimate for Davis County in column 7 of the table is calculated as $\$ 4.20 \times(58,906-48,768)=\$ 42,580$ and Davis County's high cost estimate equals $\$ 9.25 \times(58,906-48,768)=\$ 93,777$, and so on for the remaining counties. Clearly, cost estimates are largest for Salt Lake and Utah Counties, where the reductions in vehicle trips are estimated to have been the highest.

To determine the county-wide reductions in vehicle trips, we extracted daily trip-count data from [28] for the months of March-April, 2019 and March-April, 2020 from two randomly selected automatic traffic recording stations (ATRs) in Salt Lake County and one ATR each in Davis, Utah, and Weber Counties. Each station is located on the main interstate highway (I-15) that runs through the heart of the Wasatch Front. The ATRs were chosen near relatively large cities in each county. The five ATRs were also chosen such that the total number of average daily vehicle trips recorded for March-April, 2019 was roughly equal to the Federal Highway Administration's (FHA's) estimated total for the Wasatch Front's I-15 corridor in 2019 of over 314,000. In this way, we effectively calibrated our choice of ATRs to the FHA's 2019 average daily vehicle-trip estimate for the Wasatch Front [34].

Choice of which ATRs to include in the estimation of county-wide trip counts is admittedly a challenge. Including too many ATRs risks double-counting trips made by a certain percentage of the same vehicles. Including too few risks under-counting the number of trips taken overall. It is precisely because of these concerns that we calibrated our choice of ATRs to the FHA's 2019 average daily vehicle-trip estimate for the Wasatch Front. By doing so, we ensure a more realistic baseline from which to compare the reductions in vehicle trips that occurred in 2020 in response to the region's COVID-19 public health order.

\section{Social Net Benefit Estimates}

Based upon the information contained in Table 1 and Table 2 in Section 3, we 
are now able to derive daily social net benefit estimates for each Wasatch Front county and the region as a whole. Estimates for the Wasatch Front region are provided in Table 3 . We see that daily social net benefit is positive for the region as a whole solely when COBRA's high daily public health benefit of $\$ 723,000$ from reduced $\mathrm{PM}_{2.5}$ and $\mathrm{NO}_{\mathrm{x}}$ concentrations (see Table 1) are weighed against the region's low vehicle-trip cost estimate of $\$ 330,544$ (see Table 2), resulting in a social net benefit of $\$ 392,456$. All other scenarios correspond with negative net benefit estimates. As expected, daily social net benefits are smallest (largest negative) for the case where COBRA's low estimates of benefits accruing solely from reductions in $\mathrm{PM}_{2.5}$ concentrations are weighed against the high vehicle-trip cost estimate.

Substituting [29]'s $\mathrm{PM}_{2.5}$ elasticity value of 1.00 for the value 1.68 from Table 2 , and then reducing the $\mathrm{NO}_{\mathrm{x}}$ elasticity estimate in Table 2 from 1.91 by the same percentage to 1.13 , reduces the positive net benefit estimate for the Wasatch Front from $\$ 392,456$ to $\$ 104,491$. The remaining negative net benefit estimates decrease by the same proportions.

The pattern of social net benefits displayed in Table 3 is not uniform across the different counties. For example, Table 4 presents the daily social net benefit estimates for Davis County, Utah. We see that the county's social net benefits are positive when COBRA's high daily public health benefit from reduced $\mathrm{PM}_{2.5}$ concentrations alone are weighed against the region's low vehicle-trip cost estimate. Davis County's daily social net benefits are positive for all scenarios associated with combined reductions in $\mathrm{PM}_{2.5}$ and $\mathrm{NO}_{\mathrm{x}}$ concentrations except when COBRA's low benefit estimate is weighed against the high vehicle-trip cost estimate.

Appendix Table A1 shows that the daily social net benefit estimates for Salt Lake County follow the same pattern as Utah County's in Table 4. However, Weber County's pattern in Appendix Table A2 resembles that for the Wasatch Front as a whole in Table 3. Table A3 reveals that Utah County's estimated daily social net benefits are negative for each scenario. Hence, the pattern of social net benefits for the Wasatch Front region are underpinned by a variety of different patterns across the region's specific counties. Generally speaking, social net benefits are higher for Davis and Salt Lake Counties than for Utah and Weber Counties.

Table 4. Daily social net benefit estimates for Davis County, Utah.

\begin{tabular}{ccccc}
\hline & \multicolumn{2}{c}{$\begin{array}{c}\text { Reductions in } \mathrm{PM}_{2.5} \\
\text { Concentrations (\$) }\end{array}$} & $\begin{array}{c}\text { Reductions in } \mathrm{PM}_{2.5} \text { and } \mathrm{NO}_{\mathrm{x}} \\
\text { Concentrations (\$) }\end{array}$ \\
\cline { 2 - 5 } & Low Benefit & High Benefit & Low Benefit & High Benefit \\
\hline Low Cost & $-18,222$ & 12,181 & 10,495 & 76,707 \\
High Cost & $-69,419$ & $-39,016$ & $-40,702$ & 25,510 \\
\hline
\end{tabular}




\section{Summary and Conclusions}

A number of natural experiments have recently found that COVID-19 restrictions imposed in nations worldwide are correlated with short-term reductionsin some cases dramatic reductions-in mobile-source air pollutants. Noticeably absent from these studies are estimates of the social net benefits associated with the changes in human behavior underlying the pandemic-induced effects. Utilizing 1) the prevailing estimate of the reduction in the average, daily $\mathrm{PM}_{2.5}$ concentration level experienced by Utah's Wasatch Front from March 2019 (pre-COVID-19 restriction period) to March 2021 (COVID-19 restriction period), and 2) our own range of estimated declines in region-wide vehicle trips recorded across the same two time periods, we have applied the EPA's Co-Benefits Risk Assessment Health Impacts Screening and Mapping Tool (COBRA) to estimate the health benefits associated with $\mathrm{PM}_{2.5}$ reductions, along with published estimates in the literature of the cost of foregone vehicle trips, to determine the social net benefits of COVID-19 restrictions in Utah's Wasatch Front.

We have found that daily social net benefit was positive during a pandemic-induced shutdown from March to April, 2020 in Utah's Wasatch Front region solely when COBRA's "high" health benefit estimate from combined reductions in $\mathrm{PM}_{2.5}$ and $\mathrm{NO}_{\mathrm{x}}$ concentrations are weighed against the region's "low" vehicle-trip cost estimate. All other scenarios correspond with negative benefit estimates, i.e., when high and low benefit estimates of reductions solely in $\mathrm{PM}_{2.5}$ concentrations as well as for combined reductions in $\mathrm{PM}_{2.5}$ and $\mathrm{NO}_{\mathrm{x}}$ concentrations are weighed against the region's high vehicle-trip cost estimate. The pattern of social net benefits for the Wasatch Front region is underpinned by a variety of different patterns across the region's specific counties. Generally speaking, social net benefits are higher for Davis and Salt Lake Counties than for Utah and Weber Counties.

Our results, therefore, suggest that the mitigatory effects of COVID-19 restrictions on metropolitan-area pollution levels reported in several previous studies should be interpreted with a degree of caution. While obviously worth heralding, the pandemic-induced reductions in air pollution levels estimated in these studies may nevertheless fail to pass social cost-benefit tests when the economic costs of what was foregone to achieve the reductions are accounted for. The method we have used here to estimate the social net benefits associated with a short-term shock to society, such as the imposition of COVID-19 restrictions, demonstrates how limited, secondary data on changes in human behavior can be leveraged to more fully assess the extent to which the shock has altered economic outcomes. Here, "limited" refers to the availability of only highly aggregated data, such as, in our case, year-on-year, region-wide vehicle trip data and similarly aggregated pollution concentration data. When the shock in question pertains to environmental health, e.g., the effects of elevated pollution concentrations on a given population, a tool designed to convert changed concentration levels into corresponding damage estimates, such as COBRA, is necessary. This 
necessity in turn emerges as the method's key limitation.

\section{Conflicts of Interest}

The authors declare no conflicts of interest regarding the publication of this paper.

\section{References}

[1] Drouhot, L.G., Petermann, S., Schönwälder, K. and Vertovek, S. (2021) Has the Covid-19 Pandemic Undermined Public Support for a Diverse Society? Evidence from a Natural Experiment in Germany. Ethnic and Racial Studies, 44, 877-892. https://doi.org/10.1080/01419870.2020.1832698

[2] Cross, J. and Uhrig, R. (2020) Do Fans Impact Sports Outcomes? A COVID-19 Natural Experiment. https://ssrn.com/abstract=3705085 https://doi.org/10.2139/ssrn.3705085

[3] Moultrie, T.A., Dorrington, R.E., Laubscher, R., Groenewald, P., Parry, C.D.H., Matzopoulos, R. and Bradshaw, D. (2021) Unnatural Deaths, Alcohol Bans and Curfews: Evidence from a Quasi-Natural Experiment during COVID-19. South African Medical Journal. https://doi.org/10.7196/SAMJ.2021.v111i9.15813

[4] Song, Y., Li, Z., Liu, J., Yang, T., Zhang, M. and Pang, J. (2021) The Effect of Environmental Regulation on Air Quality in China: A Natural Experiment during the COVID-19 Pandemic. Atmospheric Pollution Research, 12, 21-30. https://doi.org/10.1016/j.apr.2021.02.010

[5] Zhang, J., Li, H., Lei, M. and Zhang, L. (2021) The Impact of the COVID-19 Outbreak on the Air Quality in China: Evidence from a Quasi-Natural Experiment. Journal of Cleaner Production, 296, Article ID: 126475. https://doi.org/10.1016/j.jclepro.2021.126475

[6] Huang, X. and Ding, A. (2021) Enhanced Secondary Pollution Offset Reduction of Primary Emissions during COVID-19 Lockdown in China. National Science Review, 8, nwaa137. https://doi.org/10.1093/nsr/nwaa137

[7] Wu, Q., Tang, Y., Wang, L., Wang, S., Han, D., Ouyang, D., Jiang, Y., Xu, P., Xue, Z. and Hu, J. (2021) Impact of Emission Reductions and Meteorology Changes on Atmospheric Mercury Concentrations during the COVID-19 Lockdown. Science of the Total Environment, 750, Article ID: 142323. https://doi.org/10.1016/j.scitotenv.2020.142323

[8] Sathe, Y., Gupta, P., Bawase, M., Lamsal, L., Patadia, F. and Thipse, F. (2021) Surface and Satellite Observations of Air Pollution in India during COVID-19 Lockdown: Implication to Air Quality. Sustainable Cities and Societies, 66, Article ID: 102688. https://doi.org/10.1016/j.scs.2020.102688

[9] Tanzer-Gruener, R., Li, J., Eilenberg, S.R., Robinson, A.L. and Presto, A.A. (2020) Impacts of Modifiable Factors on Ambient Air Pollution: A Case Study of COVID-19 Shutdowns. Environmental Science and Technology Letters, 7, 554-559. https://doi.org/10.1021/acs.estlett.0c00365

[10] Hudda, N., Simon, M.C., Patton, A.P. and Durant, J.L. (2020) Reductions in Traffic-Related Black Carbon and Ultrafine Particle Number Concentrations in an Urban Neighborhood during the COVID-19 Pandemic. Science of the Total Environment, 742, Article ID: 140931. https://doi.org/10.1016/j.scitotenv.2020.140931

[11] Woo, C., Cao, K., Liu, Y. and Li, Q. (2020) Estimated Benefits of Incremental Suppression of COVID-19 Spread. Open Access Library Journal, 7, 1-13. 
https://doi.org/10.4236/oalib.1106645

[12] Brookings Institution (2017) A Profile of Utah's Wasatch Front. Blueprint for American Prosperity. Metropolitan Policy Program.

https://www.brookings.edu/wp-content/uploads/2016/07/wasatch_font.pdf

[13] Perlich, P., Hollingshaus, M., Harris, R., Tennert, J. and Hogue, M. (2017) Utah's Long-Term Demographic and Economic Projections Summary. Research Brief: Kem C. Gardner Policy Institute.

https://gardner.utah.edu/wp-content/uploads/Projections-Brief-Final.pdf

[14] Ewing, R.H. (2008) Characteristics, Causes, and Effects of Sprawl: A Literature Review. In: Urban Ecology: An International Perspective on the Interaction between Humans and Nature, Spring, Berlin, 519-535.

https://doi.org/10.1007/978-0-387-73412-5_34

[15] Wasatch Front Regional Council (WFRC) (2017) Final Report Summary. Wasatch Front Central Corridor Study.

http://wfccstudy.org//wp-content/uploads/2017/09/WFCCS_Final_Report_Summar Y_8_5x11_8_11_17-2.pdf

[16] Acharya, R. (2017) Control of Episodic Air Pollution in Utah's Wasatch Front Region through Investment in Preventative Capital. Unpublished Manuscript. The Department of Applied Economics, Utah State University, Logan.

[17] Utah Department of Environmental Quality (UDEQ) (2018) Industry's Impact to Utah's Air.

https://documents.deq.utah.gov/air-quality/fact-sheets/DAQ-2018-001486.pdf

[18] American Lung Association (ALA) (2017) State of the Air. http://www.lung.org/our-initiatives/healthy-air/sota/city-rankings/most-polluted-ci ties.html

[19] Envision Utah (2021) Survey Results for Air Quality. https://yourutahyourfuture.org/images/pdfs-doc/Results_Release_Air_Quality_Fina 1.pdf

[20] Alliance for a Better Utah (2017) Clean Air Caucus. https://betterutah.org/clean-air-caucus

[21] Utah Division of Motor Vehicles (UDMV) (2017) Utah Emissions Testing. https://www.dmv.com/ut/utah/emissions-testing

[22] Utah Department of Transportation (UDOT) (2017) TravelWise: Rethink Your Trip. https://travelwise.utah.gov/about-us

[23] Mitchell, L. (2020) Air Quality Improvements during the March-April COVID-19 Lockdown. COVID-19 and Air Quality in Utah. Department of Atmospheric Sciences, University of Utah, Salt Lake City.

https://atmos.utah.edu/air-quality/covid-19_air_quality.php

[24] Harris, E. (2020) State and County Population Estimates for Utah: 2020. Research Brief. Kem C. Gardner Policy Institute, University of Utah, Salt Lake City.

[25] Salt Lake County Health Department (2021) Healthy Salt Lake. http://www.healthysaltlake.org/tiles/index/display?alias=healthdata

[26] Institute for Health Metrics and Evaluation (2021) US Health Map | Viz Hub. University of Washington, Seattle. https://vizhub.healthdata.org/subnational/usa

[27] United States Environmental Protection Agency (EPA) (1999) Nitrogen Oxides $\left(\mathrm{NO}_{x}\right)$, Why and How They Are Controlled. Technical Bulletin, EPA 456/F-99-006R. Office of Air Quality Planning and Standards, Research Triangle Park. https://www3.epa.gov/ttn/catc/dir1/fnoxdoc.pdf 
[28] Utah Department of Transportation (UDOT) (2021) Freeway and Recreational Daily Volume. UDOT COVID-19 Data Reporting. https://sites.google.com/utah.gov/udotcovid-19

[29] Moscardini, L. and Caplan, A.J. (2017) Controlling Episodic Air Pollution with a Seasonal Gas Tax: The Case of Cache Valley, Utah. Environmental and Resource Economics, 66, 689-715. https://doi.org/10.1007/s10640-015-9968-Z

[30] Small, K.A. (2012) Valuation of Travel Time. Economics of Transportation, 1, 2-14. https://doi.org/10.1016/j.ecotra.2012.09.002

[31] Caplan, A.J., Akhundjanov, S.B. and Toll, K. (2021) Measuring Heterogeneous Preferences for Residential Amenities. Regional Science and Urban Economics, 87, Article ID: 103646. https://doi.org/10.1016/j.regsciurbeco.2021.103646

[32] United States Bureau of Labor Statistics (BLS) (2020). https://bls.gov/oes/current/oes-ut.htm

[33] Van Ommeren, J. and Fosgerau, M. (2009) Workers' Marginal Costs of Commuting. Journal of Urban Economics, 65, 38-47. https://doi.org/10.1016/j.jue.2008.08.001

[34] Federal Highway Administration (FHA) (2021) Top 25 Most Traveled Locations by Average Annual Daily Traffic (AADT). Office of Highway Policy Information. 2019 Highway performance Monitoring System (HPMS).

https://www.fhwa.dot.gov/policyinformation/tables/02.cfm 


\section{Appendix}

Table A1. Daily social net benefit estimates for Salt Lake County, Utah.

\begin{tabular}{ccccc}
\hline & \multicolumn{2}{c}{$\begin{array}{c}\text { Reductions in } \mathrm{PM}_{2.5} \\
\text { Concentrations (\$) }\end{array}$} & \multicolumn{2}{c}{$\begin{array}{c}\text { Reductions in } \mathrm{PM}_{2.5} \text { and } \\
\mathrm{NO}_{\mathbf{x}} \text { Concentrations (\$) }\end{array}$} \\
\cline { 2 - 5 } & Low Benefit & High Benefit & Low Benefit & High Benefit \\
\hline Low Cost & $-58,437$ & 47,953 & 52,931 & 298,661 \\
High Cost & $-230,829$ & $-124,439$ & $-119,461$ & 126,270 \\
\hline
\end{tabular}

Table A2. Daily social net benefit estimates for Weber County, Utah.

\begin{tabular}{ccccc}
\hline & \multicolumn{2}{c}{$\begin{array}{c}\text { Reductions in } \mathrm{PM}_{2.5} \\
\text { Concentrations (\$) }\end{array}$} & \multicolumn{2}{c}{$\begin{array}{c}\text { Reductions in } \mathrm{PM}_{2.5} \text { and } \\
\mathrm{NO}_{\mathbf{x}} \text { Concentrations (\$) }\end{array}$} \\
\cline { 2 - 5 } & Low Benefit & High Benefit & Low Benefit & High Benefit \\
\hline Low Cost & $-35,817$ & $-17,392$ & $-16,338$ & 26,411 \\
High Cost & $-590,114$ & $-78,184$ & $-77,130$ & $-34,381$ \\
\hline
\end{tabular}

Table A3. Daily social net benefit estimates for Utah County, Utah.

\begin{tabular}{ccccc}
\hline & \multicolumn{2}{c}{$\begin{array}{c}\text { Reductions in } \mathrm{PM}_{2.5} \\
\text { Concentrations (\$) }\end{array}$} & \multicolumn{2}{c}{$\begin{array}{c}\text { Reductions in } \mathrm{PM}_{2.5} \text { and } \\
\mathrm{NO}_{\mathbf{x}} \text { Concentrations (\$) }\end{array}$} \\
\cline { 2 - 5 } & Low Benefit & High Benefit & Low Benefit & High Benefit \\
\hline Low Cost & $-80,198$ & $-62,989$ & $-56,279$ & -9324 \\
High Cost & $-193,258$ & $-176,048$ & $-169,338$ & $-122,384$ \\
\hline
\end{tabular}

